\title{
Neuromorphological Changes following Selection for Tameness and Aggression in the Russian Farm-Fox experiment
}

\author{
${ }^{\circledR}$ Erin E. Hecht, ${ }^{1}$ Anna V. Kukekova, ${ }^{2}$ David A. Gutman, ${ }^{3}$ Gregory M. Acland, ${ }^{4}{ }^{\circledR}$ Todd M. Preuss, ${ }^{5}$ and \\ Lyudmila N. Trut ${ }^{6}$ \\ ${ }^{1}$ Department of Human Evolutionary Biology, Harvard University, Cambridge, MA 02138, ${ }^{2}$ Department of Animal Sciences, College of Agriculture, \\ Consumer, and Environmental Sciences, University of IL Urbana-Champaign, Urbana, IL 61801, ${ }^{3}$ School of Medicine, Emory University, Atlanta, GA 30322, \\ ${ }^{4}$ Baker Institute for Animal Health, College of Veterinary Medicine, Cornell University, Ithaca, New York, $14853,{ }^{5}$ Yerkes National Primate Research Center, \\ Emory University, Atlanta, GA 30322, and ${ }^{6}$ Institute of Cytology and Genetics, Siberian Branch of the Russian Academy of Sciences, Novosibirsk, Russia, 630090
}

The Russian farm-fox experiment is an unusually long-running and well-controlled study designed to replicate wolf-to-dog domestication. As such, it offers an unprecedented window onto the neural mechanisms governing the evolution of behavior. Here we report evolved changes to gray matter morphology resulting from selection for tameness versus aggressive responses toward humans in a sample of 30 male fox brains. Contrasting with standing ideas on the effects of domestication on brain size, tame foxes did not show reduced brain volume. Rather, gray matter volume in both the tame and aggressive strains was increased relative to conventional farm foxes bred without deliberate selection on behavior. Furthermore, tame- and aggressive-enlarged regions overlapped substantially, including portions of motor, somatosensory, and prefrontal cortex, amygdala, hippocampus, and cerebellum. We also observed differential morphologic covariation across distributed gray matter networks. In one prefrontal-cerebellum network, this covariation differentiated the three populations along the tame-aggressive behavioral axis. Surprisingly, a prefrontal-hypothalamic network differentiated the tame and aggressive foxes together from the conventional strain. These findings indicate that selection for opposite behaviors can influence brain morphology in a similar way.

Key words: aggression; canids; domestication; farm-fox experiment; neuroimaging; social behavior

Significance Statement

Domestication represents one of the largest and most rapid evolutionary shifts of life on earth. However, its neural correlates are largely unknown. Here we report the neuroanatomical consequences of selective breeding for tameness or aggression in the seminal Russian farm-fox experiment. Compared with a population of conventional farm-bred control foxes, tame foxes show neuroanatomical changes in the PFC and hypothalamus, paralleling wolf-to-dog shifts. Surprisingly, though, aggressive foxes also show similar changes. Moreover, both strains show increased gray matter volume relative to controls. These results indicate that similar brain adaptations can result from selection for opposite behavior, that existing ideas of brain changes in domestication may need revision, and that significant neuroanatomical change can evolve very quickly, within the span of $<100$ generations.

Received Dec. 11, 2020; revised May 11, 2021; accepted May 17, 2021.

Author contributions: E.E.H., A.V.K., D.A.G., T.M.P., and L.N.T. designed research; E.E.H. and A.V.K. performed research; E.E.H. contributed unpublished reagents/analytic tools; E.E.H. analyzed data; E.E.H. wrote the first draft of the paper; E.E.H., A.V.K., D.A.G., G.M.A., T.M.P., and L.N.T. edited the paper; E.E.H. wrote the paper.

E.E.H., T.M.P., D.A.G., and neuroimaging scan costs were supported by National Science Foundation IOS \#1457291. A.V.K., sample collection, and behavioral data analysis were supported by National Institutes of Health Grant GM120782. We thank Jaekeun Park and Orion Keifer for assistance with scan acquisition; Olivia Zarella and Jeromy Dooyema for assistance with sample preparation; Yury E. Herbeck and Anastasiya V. Kharlamova for insightful discussions and help in preparation of the experiments at the experimental farm of the Institute of Cytology and Genetics (Novosibirsk, Russia); and Irina V. Pivovarova, Anastasiya V. Vladimirova, Tatyana I. Semenova, Eugene A. Martinov, and all the animal keepers at the Institute of Cytology and Genetics experimental farm for research assistance. L.N.T., the fox colony, sample collection, and behavioral data analysis were supported by the Institute of Cytology and Genetics of the Siberian Branch of the Russian Academy of Sciences grant 0259-2021-0016

The authors declare no competing financial interests.

Correspondence should be addressed to Erin E. Hecht at erin_hecht@fas.harvard.edu.

https://doi.org/10.1523/JNEUROSCI.3114-20.2021

Copyright $(2021$ the authors

\section{Introduction}

Domestication refers to the process of animal adaptation to the human niche. It represents one of the largest and most rapid evolutionary shifts in life on Earth: the biomass of domesticated animals has increased an estimated 3.5 -fold in the last 100 years and now outweighs the biomass of other terrestrial mammals by a factor of $\sim 25$ (Smil, 2011). Correspondingly, the neural changes associated with domestication constitute a major event in the history of brain evolution. Moreover, self-domestication is hypothesized to have played a role in the evolution of our own species (Brune, 2007; Hare, 2017; Wrangham, 2018). However, surprisingly little is known about the neural correlates of domestication. 


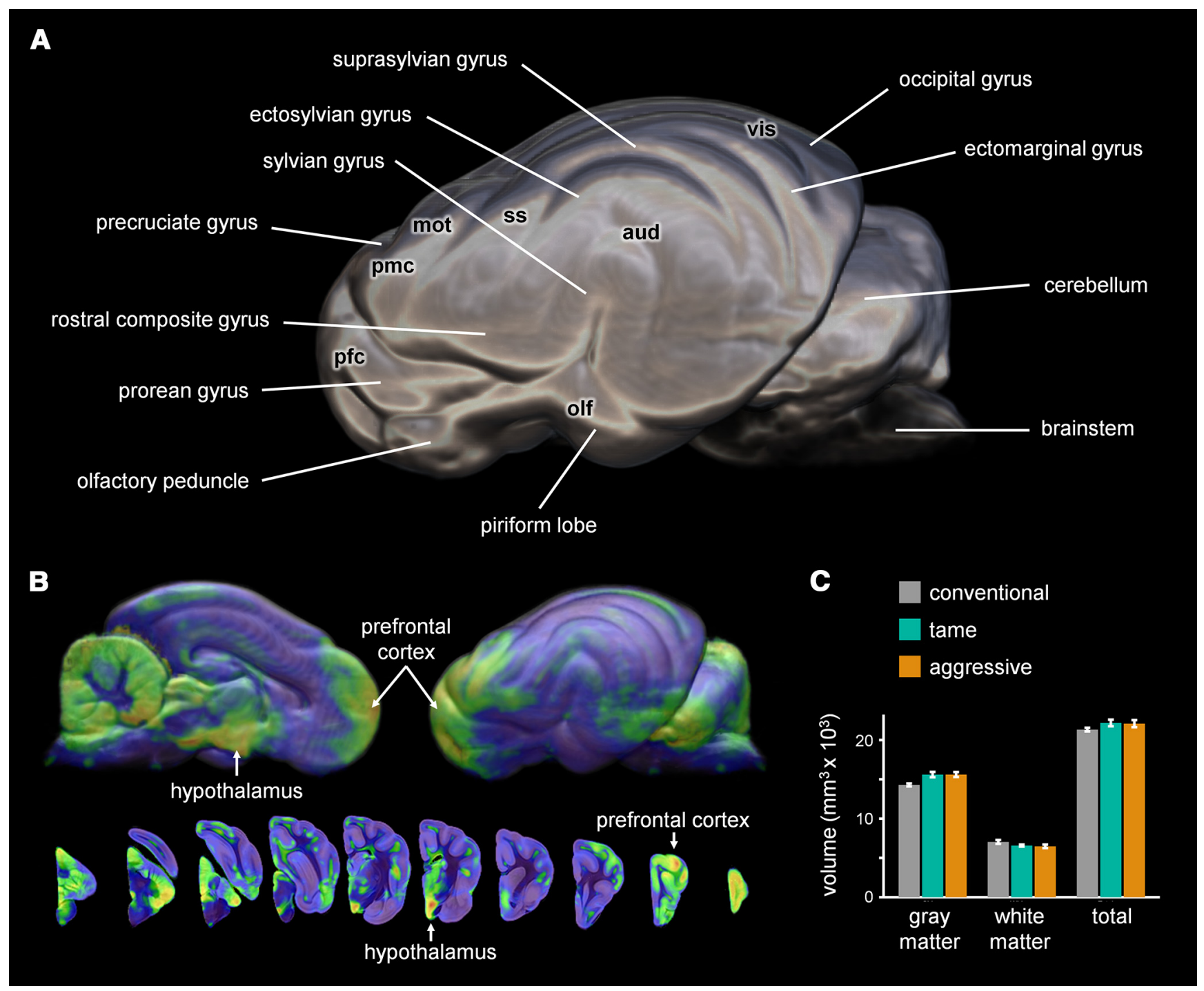

Figure 1. Brain volume shifts in the Russian farm-fox experiment. $\boldsymbol{A}$, Group-average template with anatomic labels and approximate cortical functional localizations from the dog (Evans and de Lahunta, 2013). olf, Olfactory; pfc, prefrontal; pmc, premotor; mot, motor; ss, somatosensory; aud, auditory; vis, visual. $\boldsymbol{B}$, Variation in regional morphology across the dataset. Warmer colors represent more variation. Lateral views of 3D surface renderings and coronal cross-sections are shown. C, Strain-wise differences in gray matter, white matter, and total brain volume. Error bars indicate SEM.

Perhaps the most well-known effect of domestication on the brain is a reduction in size (Kruska, 2005). Dogs are the oldest and perhaps the archetypal domesticate, having split from wolves an estimated 10,000-30,000 years ago (Skoglund et al., 2011; MacHugh et al., 2017). Past research on the neural correlates of wolf-to-dog domestication has implicated PFC and the limbic system, particularly the hypothalamo-pituitary-adrenal axis. For example, gene expression in the hypothalamus is conserved between wolves and coyotes but diverges significantly in dogs (Saetre et al., 2004). Similarly, genes showing high differentiation between wolves and Chinese native dogs show high expression bias for the brain, particularly those expressed in PFC (Li et al., 2013). In an MRI study of 8 wild carnivore species and 13 domestic dogs, the allometric scaling of corpus callosum size to total brain size was constant across species, except in the rostral component, which interconnects prefrontal cortices (Spocter et al., 2018). Moreover, the enlargement of one component of carnivore PFC, the prorean gyrus, which has extensive connections with other limbic system components (Cavada and ReinosoSuárez, 1985; Markow-Rajkowska and Kosmal, 1987), has been implicated in the emergence of complex social behavior in canid evolution (Radinsky, 1969).

The domestication of wolves into dogs is paralleled by the well-known and long-running Russian fox experiment (Trut et al., 2009). The experiment does not, of course, perfectly recapitulate the "naturally" occurring domestication of any species, and indeed domestication trajectories differ in important ways across species and can involve selection pressures beyond tameness (Zeder, 2012). Nonetheless, the Russian fox experiment offers a singularly well-controlled window on neurobiological shifts associated with tameness (Zeder, 2012). Since 1959, researchers at the Institute of Cytology and Genetics in Novosibirsk have been breeding conventional farm foxes on the basis of their behavioral response to human social contact. The tame strain is selected for high social approach behavior toward humans and produces dog-like behaviors, such as licking and tail wagging. In a parallel experiment, the aggressive strain is selected for the opposite behavior and reacts with defensive aggression when faced with human contact. A third conventional strain 
Table 1. Trait loadings for PCA of behavior

\begin{tabular}{|c|c|c|c|c|}
\hline Trait & Trait description & PC1 & PC2 & $\mathrm{PC3}$ \\
\hline C 37 & Aggressive sounds & -0.1476673 & 0.2057388 & 0.05690569 \\
\hline A52 & Did not come to zone $2 a$ & -0.1430533 & -0.0512895 & -0.0320838 \\
\hline C34 & Follows the hand (aggressive) & -0.1402881 & 0.23863637 & 0.07126363 \\
\hline C31 & Attack alert & -0.1399264 & 0.2314992 & 0.06913457 \\
\hline C 32 & Pinned ears (aggressive) & -0.133127 & 0.1853784 & 0.07517754 \\
\hline D31 & Not on the floor of zone 2 & -0.1304852 & -0.0279166 & -0.1040545 \\
\hline B12 & Not on the floor of zone 2 & -0.1286657 & -0.1034625 & 0.15847715 \\
\hline A25 & Spend in zones 3, 4-6 at least $40 \mathrm{~s}$ & -0.1145566 & -0.1145345 & -0.1041976 \\
\hline C36 & Triangle ears directed back (aggressive) & -0.1084682 & 0.1639514 & 0.06852387 \\
\hline B25 & Pinned ears (aggressive) & -0.1030547 & 0.12176326 & -0.0338697 \\
\hline B29 & Spend in zone $3,4-6$ at least $40 \mathrm{~s}$ & -0.0979483 & -0.1150948 & 0.18041277 \\
\hline C 30 & Attack & -0.0811832 & 0.20157786 & 0.02742591 \\
\hline $\mathrm{C} 33$ & Trying to bite & -0.0787731 & 0.18749222 & 0.09395528 \\
\hline B30 & Spend in zones 5 and 6 at least $40 \mathrm{~s}$ & -0.0763434 & -0.1219152 & -0.040511 \\
\hline B42 & Keeping same posture and place for at least $40 \mathrm{~s}$ & -0.0746656 & -0.0280051 & -0.1063443 \\
\hline B13 & Not on the floor of zone $2 a$ & -0.0730084 & -0.0776614 & 0.14535304 \\
\hline B2 & Immediately moved back to zone 5 or zones 3,5 , and 6 & -0.0667175 & -0.1315815 & 0.16132763 \\
\hline A23 & Moving back for at least one zone during first $15 \mathrm{~s}$ & -0.0635934 & -0.0798363 & 0.04627051 \\
\hline A40 & Keep same posture and place at least for $40 \mathrm{~s}$ & -0.0610294 & -0.0451188 & -0.0882064 \\
\hline $\mathrm{C} 38$ & Animal is present only in zones 3,5 , and 6 & -0.0603003 & -0.2143789 & 0.06897475 \\
\hline D39 & Pinned ears (aggressive) & -0.0589739 & 0.07022877 & -0.0544917 \\
\hline C4 & Spend more than $30 \mathrm{~s}$ in zones $3-6$ & -0.0486048 & -0.1129164 & 0.1191827 \\
\hline C7 & First time can touch a fox in zones 5 and 6 & -0.0442354 & -0.2005908 & 0.16847207 \\
\hline A31 & Lie in any zone longer than $30 \mathrm{~s}$ & -0.0413531 & -0.0473826 & -0.0526588 \\
\hline C3 & Animal is in zones 3-6 in the beginning of step C & -0.0359193 & -0.0807357 & 0.10769476 \\
\hline $\mathrm{C} 55$ & Leaning on side or back walls in zones 5 and 6 & -0.0357765 & -0.0621933 & 0.09883121 \\
\hline A32 & Lie in any zone a whole minute & -0.0322557 & -0.0455808 & -0.0514736 \\
\hline $\mathrm{C} 35$ & Narrow ears directed back & -0.0134525 & -0.1674438 & 0.07190769 \\
\hline B37 & Stays on back or side walls in zones 5 and 6 & -0.0067197 & -0.0593972 & 0.07711811 \\
\hline B48 & Ears are vertical & -0.0051633 & -0.0905863 & 0.21988206 \\
\hline B14 & Sniffing floor/air & 0.00665074 & -0.0271967 & 0.12153536 \\
\hline A48 & Sit for at least $20 \mathrm{~s}$ & 0.00809613 & -0.029441 & -0.0223952 \\
\hline $\mathrm{C} 50$ & Tail is up for at least for $3 \mathrm{~s}$ & 0.01117132 & 0.03423211 & 0.11681401 \\
\hline B9 & Sniffing hand from small distance & 0.01562686 & -0.0104944 & 0.12987889 \\
\hline A34 & Changed place at least once & 0.02762113 & 0.01619735 & 0.0878816 \\
\hline A38 & Did at least one full circle & 0.03153232 & -0.0493083 & 0.12161341 \\
\hline B8 & Come to the hand after $10 \mathrm{~s}$ & 0.03582494 & -0.0003365 & 0.07587808 \\
\hline A36 & Changed place at least 2-4 times & 0.03677646 & 0.01294125 & 0.10609875 \\
\hline D13 & Grooming & 0.03813346 & -0.0131906 & 0.00017673 \\
\hline B39 & Changed place at least 2-4 times & 0.0453691 & 0.00602985 & 0.0943546 \\
\hline $\mathrm{C} 2$ & Animal is in zones 1 and $2-4$ in the beginning of step C & 0.04645646 & 0.10165381 & -0.0895807 \\
\hline A47 & Tail is up for at least $3 \mathrm{~s}$ & 0.05655872 & 0.00542154 & 0.05048287 \\
\hline B47 & Tail is up for at least $3 \mathrm{~s}$ & 0.05926645 & 0.00639307 & 0.08498355 \\
\hline B32 & Moving on "short legs" & 0.06011035 & 0.0280033 & -0.0825452 \\
\hline C39 & Moved forward for at least one zone during the step & 0.06502536 & 0.13752432 & 0.04538581 \\
\hline $\mathrm{C} 204$ & Tame sounds (combined) & 0.06680337 & 0.00121025 & -0.0599009 \\
\hline D33 & Tail is up for at least $3 \mathrm{~s}$ & 0.0674776 & -0.0014009 & 0.01885399 \\
\hline B19 & Loud breathing & 0.06814984 & 0.0352152 & -0.124301 \\
\hline B3 & Touch hand for at least $40 \mathrm{~s}$ & 0.06946151 & 0.04423451 & -0.1249051 \\
\hline D25 & Moving forward for at least one zone during first $15 \mathrm{~s}$ & 0.07393203 & -0.0237983 & 0.10749179 \\
\hline B1 & Animal is in zone 2 in the beginning & 0.07482935 & 0.08558415 & -0.1237285 \\
\hline $\mathrm{C} 25$ & Tail wagging & 0.07724832 & -0.0012107 & -0.0996494 \\
\hline C6 & First time can touch a fox in zones 3 and 4 & 0.0797726 & -0.0387303 & 0.01207579 \\
\hline $\mathrm{C} 18$ & Hold hand & 0.08141347 & -0.0092092 & -0.061069 \\
\hline D29 & Did at least one full circle & 0.084554 & -0.0796958 & 0.09728685 \\
\hline A37 & Changed place at least 5 times & 0.08626927 & 0.01591251 & 0.17384956 \\
\hline $\mathrm{C} 17$ & Rolls on the side, ask to touch belly & 0.08742998 & $7.45 \mathrm{E}-05$ & -0.0816944 \\
\hline A7 & Touch door by foot or scratch & 0.08991397 & 0.0532481 & -0.0091076 \\
\hline A29 & Came to zones 1 and 2 & 0.09018569 & 0.0465907 & 0.15163891 \\
\hline B40 & Changed place at least 5 times & 0.09072512 & -0.0165086 & 0.1744323 \\
\hline $\mathrm{C} 13$ & Allows to touch back part of the back & 0.09318948 & -0.2048051 & 0.00241271 \\
\hline D24 & Comes to zones 1 and 2 & 0.0959737 & 0.01736351 & 0.12844973 \\
\hline $\mathrm{A} 2$ & Tail wagging & 0.10156213 & 0.02488945 & -0.0929812 \\
\hline D28 & Changes place at least 5 times & 0.10330463 & -0.0334257 & $\begin{array}{r}0.11796783 \\
\text { (Table continues.) }\end{array}$ \\
\hline
\end{tabular}


Table 1. Continued

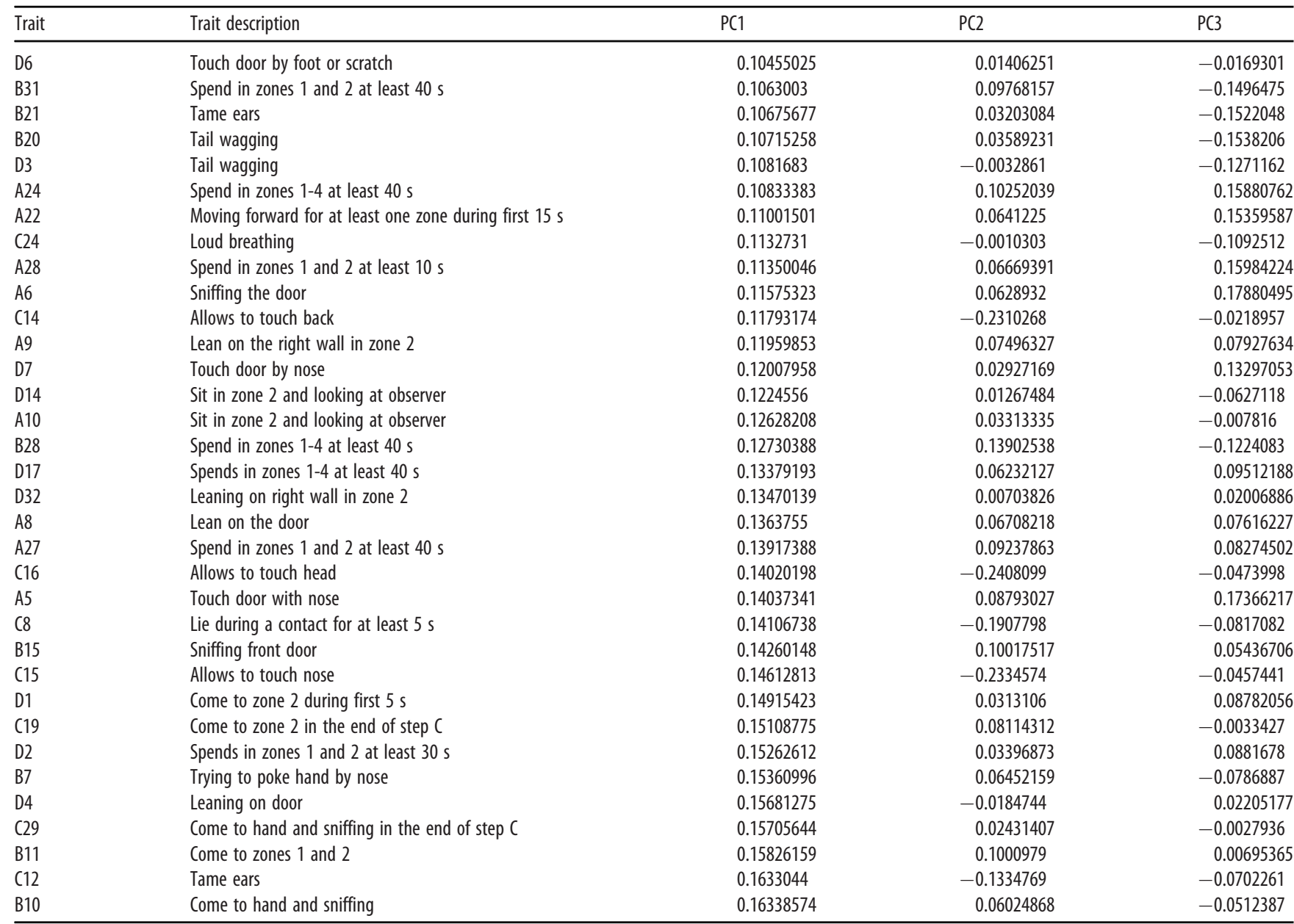

Trait loadings for PCA of behavior sorted by PC1. The letter in the trait name indicates a test step (A - observer stands calmly near the closed cage; $\mathbf{B}$ - observer opens the cage door, but does not initiate any contact with the fox; C - observer attempts to touch the fox; D -observer closes the cage door, then remains calmly near the closed cage) (see Kukekova et al., 2011a for details).

is kept on the farm but bred without deliberate selection on behavior (Statham et al., 2011). Behavioral differences between tame and aggressive foxes map to a locus on fox chromosome 12, which is homologous to the locus implicated in wolf-to-dog domestication (Kukekova et al., 2011a, 2012) and the whole-genome sequencing of tame, aggressive, and conventional foxes identifies 103 genomic regions differentiating the three populations including 46 regions, which are syntenic to canine candidate domestication regions (Kukekova et al., 2018). Differential gene expression across strains has been established in PFC, basal forebrain, hypothalamus, and anterior pituitary (Kukekova et al., 2011b; Hekman et al., 2018; Wang et al., 2018; Rosenfeld et al., 2020). Additionally, tame foxes show increased adult neurogenesis in the hippocampus in comparison to conventional foxes (Huang et al., 2015). However, the brain-wide neuroanatomical consequences of selection on behavior in the fox model are as yet unknown. In this study, we addressed this question using high-resolution, T2-weighted, whole-brain ex vivo neuroimaging in 10 tame, 10 aggressive, and 10 conventional foxes. These were the same individuals used in previous transcriptomic studies (Kukekova et al., 2011a, 2012), and their behavior was tested and analyzed as previously described (Kukekova et al., 2008). We conducted three types of analyses: a comparison of overall gray matter, white matter, and total brain volumes; a comparison of differences in regional gray matter volumes across strains; and a comparison of strain-wise differences in anatomic covariation across regions, which can identify morphologically coevolving structural networks and link them to individual variation in behavior.

\section{Materials and Methods}

Brain specimens. In the current study, we examined the brains of 10 tame, 10 conventional, and 10 aggressive foxes. All foxes were housed with littermates and mother from birth until weaning at 6 weeks, then housed with littermates for a further 4 weeks, and then singly housed in a shed for young foxes with members of the same strain until $\sim 7$ months of age. After that, all 30 foxes used in this experiment were singly housed in the same shed for adult foxes. At all stages of rearing and maintenance, fox interaction with humans was limited to feeding, veterinary care, and testing behavior in home cages at 5.5-6 months of age. All foxes were male, sexually naive, and $\sim 1.5$ years old at the time of brain extraction in August of 2010. Right hemispheres were preserved for gene expression studies; we report analyses in left hemispheres here. Left hemispheres were formalin-fixed and were maintained in formalin solution until scanning in 2016.

Neuroimaging data acquisition. For imaging, brains were placed in a waterproof plastic container, which was packed with polyethylene beads for stabilization. The container was then pumped full of Fluorinert FC$770(3 \mathrm{M})$. Fluorinert is a fluorocarbon; it is analogous to a hydrocarbon, but with fluorine taking the place of hydrogen. It thus produces no signal in (typical) MRI, which is tuned to the resonant frequency of hydrogen nuclei. Images were acquired on a $9.4 \mathrm{~T} / 20 \mathrm{~cm}$ horizontal bore Bruker magnet, interfaced to an Avance console, with Paravision 5.1 software 
(Bruker). A 7.2-cm-diameter volume radio frequency coil was used for transmission and reception with a RARE T2 sequence ( 2 averages, $13 \mathrm{~ms}$ TE, $2500 \mathrm{~ms}$ TR, rare factor 8). Image resolution was $300 \mu \mathrm{m}^{3}$ with a matrix size of $256 \times 100 \times 88$.

Image analysis. Image preprocessing was accomplished using the FSL software package (Smith et al., 2004; Woolrich et al., 2009; Jenkinson et al., 2012). Images underwent bias correction and segmentation into white matter and gray matter using FAST (Zhang et al., 2001). In order to provide a common spatial framework for morphometric analysis, an unbiased nonlinear template was built from the 10 conventional foxes' T2-weighted images using the ANTS software package (Avants et al., 2009). This template represents the group average morphology across the conventional fox brain specimens. All subject's T2-weighted images were nonlinearly aligned to this template. We computed the Jacobian determinant image of each deformation field; this represents a spatial map of where and how much each individual subject's scan had to deform to come into alignment with the template. The Jacobian determinant images were then masked with the gray matter segmentation images to produce representations of each subject's gray matter deviation from the template, and were then smoothed with a $0.6 \mathrm{~mm}$ (2 voxel) Gaussian kernel. Individual foxes' graymatter masked, smoothed Jacobian determinant images became the input for each of two independent, complementary statistical morphometric analyses. The average of all foxes' masked Jacobian images is shown in Figure $1 B$.

Voxel-based morphometry (VBM) (Ashburner and Friston, 2000) is an inherently hypothesis-based approach that performs GLM at each voxel in the image to determine whether morphology is significantly related to explanatory variables (e.g., group). VBM analysis was accomplished using FSL's randomize tool for voxel-wise Monte Carlo permutation testing of GLMs, which permutes explanatory variables across cases to build up a null distribution, and then tests whether observed associations to explanatory variables significantly differ from this random null distribution (Winkler et al., 2014). On the other hand, source-based morphometry (SBM) (Xu et al., 2009) is a data-driven, model-free approach that identifies patterns of significant morphologic correlation across subjects. In other words, it determines which regions of the brain significantly covary with each other across the entire dataset, while remaining agnostic to putative differences across subjects (e.g., group differences). Post hoc tests can then be used to determine whether these networks show significant associations with variables of interest. This was accomplished using the GIFT SBM toolbox for MATLAB (Xu et al., 2009; http://mialab.mrn.org/software/gift/index.html; for an in-depth discussion of the method and its applications, see Gupta et al., 2019). Multiple linear regression was then used to assess the relationship between factor loadings for covarying gray matter networks and factor loadings for a principal components analysis of fox behavioral traits described below. Past research has used SBM mainly in the context of identifying neuroanatomical differences between patient and control populations (e.g., schizophrenia) (Xu et al., 2009; Turner et al., 2012; Rodrigue et al., 2020), but several studies have also used SBM in animal studies focused on evolved traits: for example, chimpanzee tool use (Hopkins et al., 2019) and eye gaze (Hopkins et al., 2020); and breed-specialized skills in domestic dogs (Hecht et al., 2019). Covariance in morphology across regions is thought to reflect both shared genetic factors and similar patterns of development and functional specialization; these structurally covarying networks appear to be similar to functionally covarying resting state networks (AlexanderBloch et al., 2013; Evans, 2013; Gupta et al., 2019). Although SBM identifies networks of structurally covarying regions, it does not assess white matter connections linking those regions.

Assignment of fox behavioral phenotypes. Fox behavior was tested at 5.5-6 months of age in the standard test described by Kukekova et al. (2008). Fox behavior during the test was scored from the video records for 98 recordable observations (Table 1). The matrix, including scores for 1003 foxes from Kukekova et al. (2011a) and scores for 30 foxes used in this study, were subjected to principal component analysis (PCA) in R using function: prcomp. The distribution of PC1-PC3 values for 30 foxes whose brains are analyzed are shown in Figure 4.

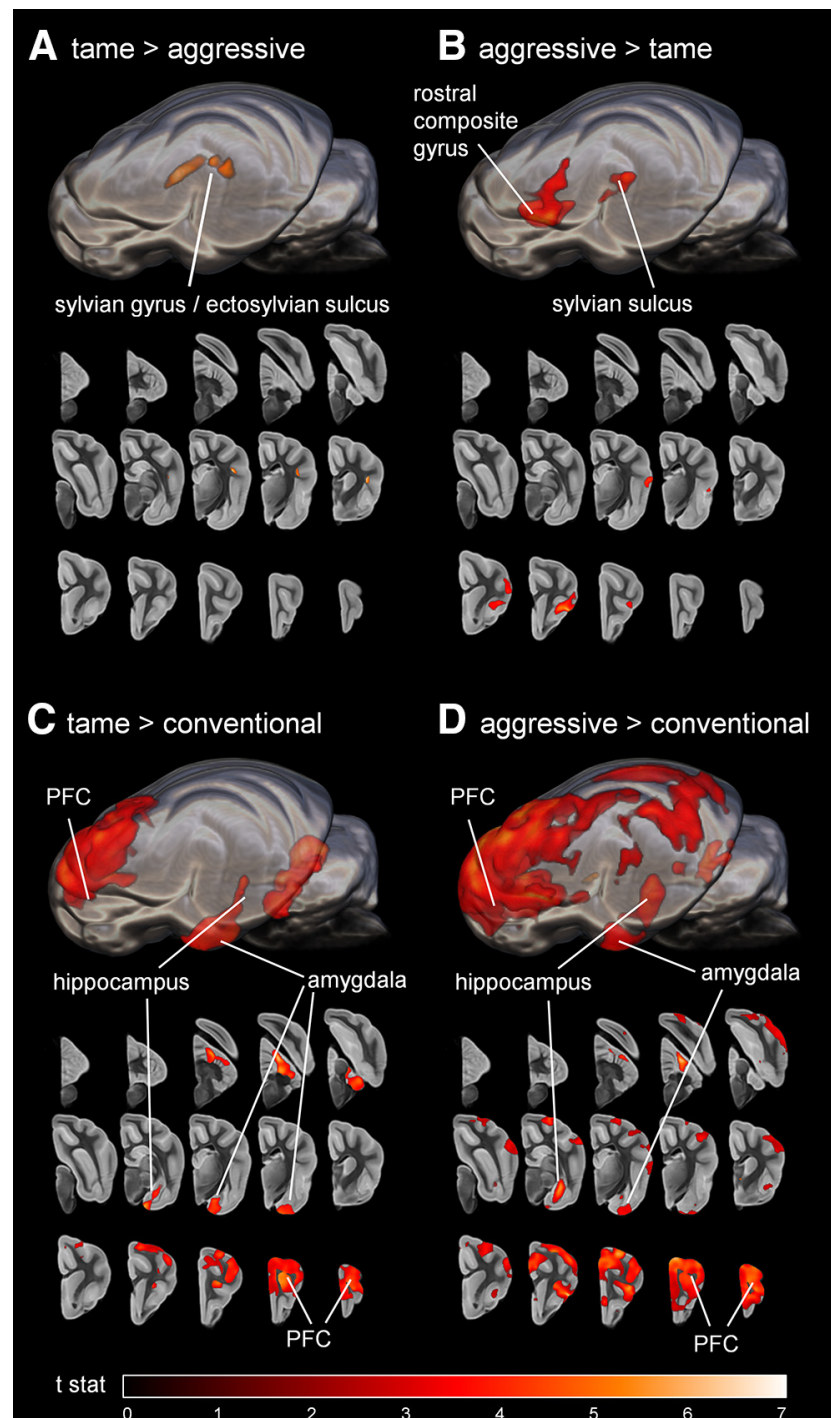

E tame \& aggressive both > conventional

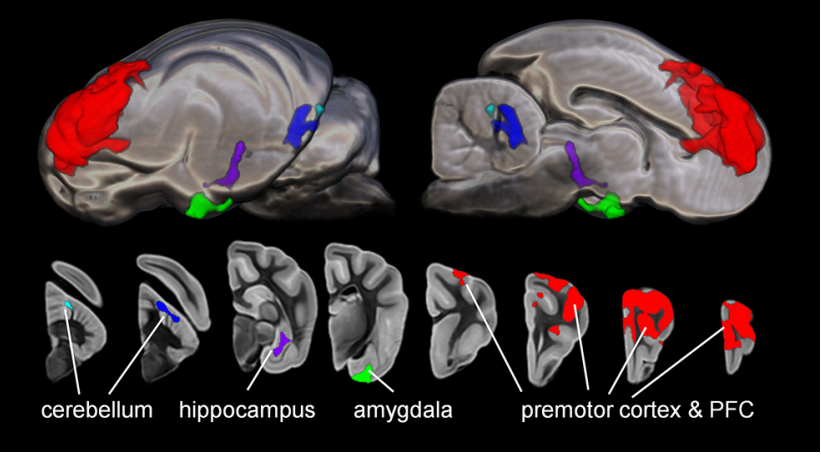

Figure 2. Differences in regional gray matter volume between strains. $\boldsymbol{A}$, Tame $>$ aggressive. $\boldsymbol{B}$, Aggressive $>$ tame. $\boldsymbol{C}$, Tame $>$ conventional. $\boldsymbol{D}$, Aggressive $>$ conventional. $\boldsymbol{E}$, Tame and aggressive both $>$ conventional. Color code: red represents frontal cortex; green represents amygdala; magenta represents hippocampus; blue and cyan represents cerebellum.

\section{Results}

The T2-weighted conventional fox brain template and labels for some anatomic regions are shown in Figure 1A. A map of variation in brain anatomy across all strains is shown in 
Table 2. Clusters resulting from VBM analysis ${ }^{a}$

\begin{tabular}{|c|c|c|c|c|c|}
\hline & $\begin{array}{l}\text { Cluster } \\
\text { index }\end{array}$ & $\begin{array}{l}\text { Volume } \\
\left(\mathrm{mm}^{3}\right)\end{array}$ & $\begin{array}{l}\text { MAX } \\
X \text { (vox) }\end{array}$ & $\begin{array}{l}\text { MAX } \\
Y \text { (vox) }\end{array}$ & $\begin{array}{l}\text { MAX } \\
Z \text { (vox) }\end{array}$ \\
\hline \multicolumn{6}{|l|}{ Tame $>$ Aggressive } \\
\hline & 1 & 31.941 & 56 & 162 & 77 \\
\hline & & & 55 & 160 & 79 \\
\hline & & & 59 & 140 & 86 \\
\hline & & & 62 & 132 & 82 \\
\hline & & & 55 & 150 & 86 \\
\hline \multicolumn{6}{|l|}{ Tame $<$ Aggressive } \\
\hline & 2 & 198.288 & 62 & 189 & 50 \\
\hline & & & 70 & 186 & 52 \\
\hline & & & 61 & 196 & 52 \\
\hline & & & 55 & 193 & 52 \\
\hline & & & 59 & 175 & 59 \\
\hline & & & 72 & 180 & 72 \\
\hline & 1 & & 79 & 139 & 76 \\
\hline & & & 74 & 141 & 73 \\
\hline & & & 68 & 154 & 63 \\
\hline \multicolumn{6}{|l|}{ Tame $>$ Conventional } \\
\hline & 3 & 1095.957 & 32 & 222 & 69 \\
\hline & & & 33 & 223 & 67 \\
\hline & & & 36 & 222 & 78 \\
\hline & & & 40 & 226 & 56 \\
\hline & & & 46 & 207 & 64 \\
\hline & & & 56 & 210 & 86 \\
\hline & 2 & 303.183 & 34 & 98 & 59 \\
\hline & & & 32 & 85 & 77 \\
\hline & & & 35 & 73 & 79 \\
\hline & & & 35 & 86 & 62 \\
\hline & & & 48 & 100 & 47 \\
\hline & & & 42 & 96 & 46 \\
\hline & 1 & 185.22 & 36 & 129 & 27 \\
\hline & & & 36 & 151 & 18 \\
\hline & & & 54 & 122 & 59 \\
\hline & & & 38 & 141 & 33 \\
\hline & & & 39 & 145 & 27 \\
\hline & & & 44 & 133 & 38 \\
\hline \multirow{27}{*}{$\begin{array}{l}\text { Tame }<\text { Conventional } \\
\text { Aggressive }>\text { Conventional }\end{array}$} & (none) & & & & \\
\hline & 11 & 2309.283 & 37 & 222 & 79 \\
\hline & & & 63 & 190 & 49 \\
\hline & & & 31 & 223 & 70 \\
\hline & & & 61 & 198 & 51 \\
\hline & & & 56 & 202 & 58 \\
\hline & & & 29 & 217 & 93 \\
\hline & 10 & 440.505 & 42 & 130 & 130 \\
\hline & & & 78 & 123 & 104 \\
\hline & & & 41 & 121 & 130 \\
\hline & & & 77 & 96 & 90 \\
\hline & & & 42 & 140 & 129 \\
\hline & & & 42 & 143 & 128 \\
\hline & 9 & 104.652 & 48 & 149 & 17 \\
\hline & & & 49 & 141 & 17 \\
\hline & & & 54 & 149 & 18 \\
\hline & & & 52 & 145 & 27 \\
\hline & & & 39 & 148 & 17 \\
\hline & & & 35 & 129 & 26 \\
\hline & 8 & 93.717 & 54 & 125 & 51 \\
\hline & & & 61 & 122 & 51 \\
\hline & & & 46 & 141 & 37 \\
\hline & 7 & 52.083 & 36 & 90 & 70 \\
\hline & & & 44 & 86 & 69 \\
\hline & & & 46 & 77 & 75 \\
\hline & & & 53 & 79 & 70 \\
\hline & 6 & 22.896 & 81 & 132 & 75 \\
\hline
\end{tabular}

Table 2. Continued

\begin{tabular}{|c|c|c|c|c|c|}
\hline & $\begin{array}{l}\text { Cluster } \\
\text { index }\end{array}$ & $\begin{array}{l}\text { Volume } \\
\left(\mathrm{mm}^{3}\right)\end{array}$ & $\begin{array}{l}\text { MAX } \\
X \text { (vox) }\end{array}$ & $\begin{array}{l}\text { MAX } \\
Y \text { (vox) }\end{array}$ & $\begin{array}{l}\text { MAX } \\
Z \text { (vox) }\end{array}$ \\
\hline & & & 80 & 139 & 75 \\
\hline & & & 78 & 142 & 65 \\
\hline & 5 & 9.855 & 52 & 107 & 70 \\
\hline & & & 46 & 103 & 63 \\
\hline & 4 & 3.402 & 26 & 163 & 58 \\
\hline & & & 30 & 157 & 62 \\
\hline & 3 & 3.348 & 33 & 74 & 82 \\
\hline & 2 & 0.567 & 64 & 145 & 59 \\
\hline Aggressive $<$ Conventional & $\begin{array}{c}1 \\
\text { (none) }\end{array}$ & 0.486 & 42 & 206 & 30 \\
\hline
\end{tabular}

${ }^{a}$ Each component contains multiple clusters, indicated by Cluster index. Voxel coordinates are for maximum value in cluster.

Figure $1 B$; a graph of gray matter, white matter, and total brain volumes for each strain are shown in Figure $1 C$. Oneway ANOVAs revealed a strain-wise difference in total gray matter volume $\left(F_{(2,27)}=6.855, p=0.004\right)$. Post hoc Tukey's HSD tests indicated that both tame and aggressive foxes had significantly higher gray matter volume than conventional foxes (tame $>$ conventional: $t_{(18)}=3.370, p=0.003$; aggressive $>$ conventional: $\left.t_{(18)}=3.556, p=0.002\right)$, but did not differ significantly from each other $\left(t_{(18)}=0.010, p=0.992\right)$. Strain-wise differences in white matter volume and total brain volume did not reach significance (white matter: $F_{(2,27)}=2.186, p=0.132$; total brain volume: $\left.F_{(2,27)}=1.504, p=0.240\right)$.

Voxel-based morphometry identified a number of differences between strains (Fig. 2). Carnivore cortical mapping studies have been most extensive in cats and ferrets, but relatively less work has been done in dogs, which are more closely related to foxes. Thus, putative functions of anatomic regions are based on known dog anatomy here but should be considered tentative. Relative to aggressive foxes, tame foxes show expansion in portions of the sylvian gyrus and ectosylvian sulcus (temporal regions that include auditory cortex and other regions, potentially higher-order visual or multisensory cortex; Fig. 2A) (Kosmal, 2000). In contrast, compared with tame foxes, aggressive foxes show expansion in portions of the rostral composite gyrus and presylvian sulcus (potentially somatosensory and/or premotor-prefrontal transition cortex) (Kosmal et al., 1984) and in the ectosylvian and sylvian gyri and sylvian sulcus (auditory and association cortex in dogs; Fig. 2B) (Kosmal, 2000). Surprisingly, relative to the conventional strain, both tame and aggressive foxes show expansion in similar regions, including portions of the prorean, orbital, frontal, precruciate, and rostral composite gyri (prefrontal, premotor, and motor cortex in dogs) (Kosmal et al., 1984), amygdala, hippocampus, and cerebellum (Fig. 2C,D; overlap shown in Fig. 2E). No voxels showed reduced volume in tame or aggressive foxes relative to conventional foxes. Anatomical locations, maximum $t$ statistics, number of voxels, and volume for each cluster are shown in Table 2.

Notably, the hypothalamus was one of the regions with the highest volumetric variation across the entire dataset (Fig. 1B), but direct group-wise comparisons did not identify significant volumetric differences between strains (Fig. 2). Past studies on the farm-fox experiment have implicated the hypothalamo-pituitary-adrenal axis generally (for review, see Trut et al., 2009) and gene expression in the hypothalamus specifically (Rosenfeld et al., 2020). Neuroanatomical consequences of rapid selection on behavior can be visible not only in changes to relative volume of brain regions, but also in the degree of morphologic correlation 

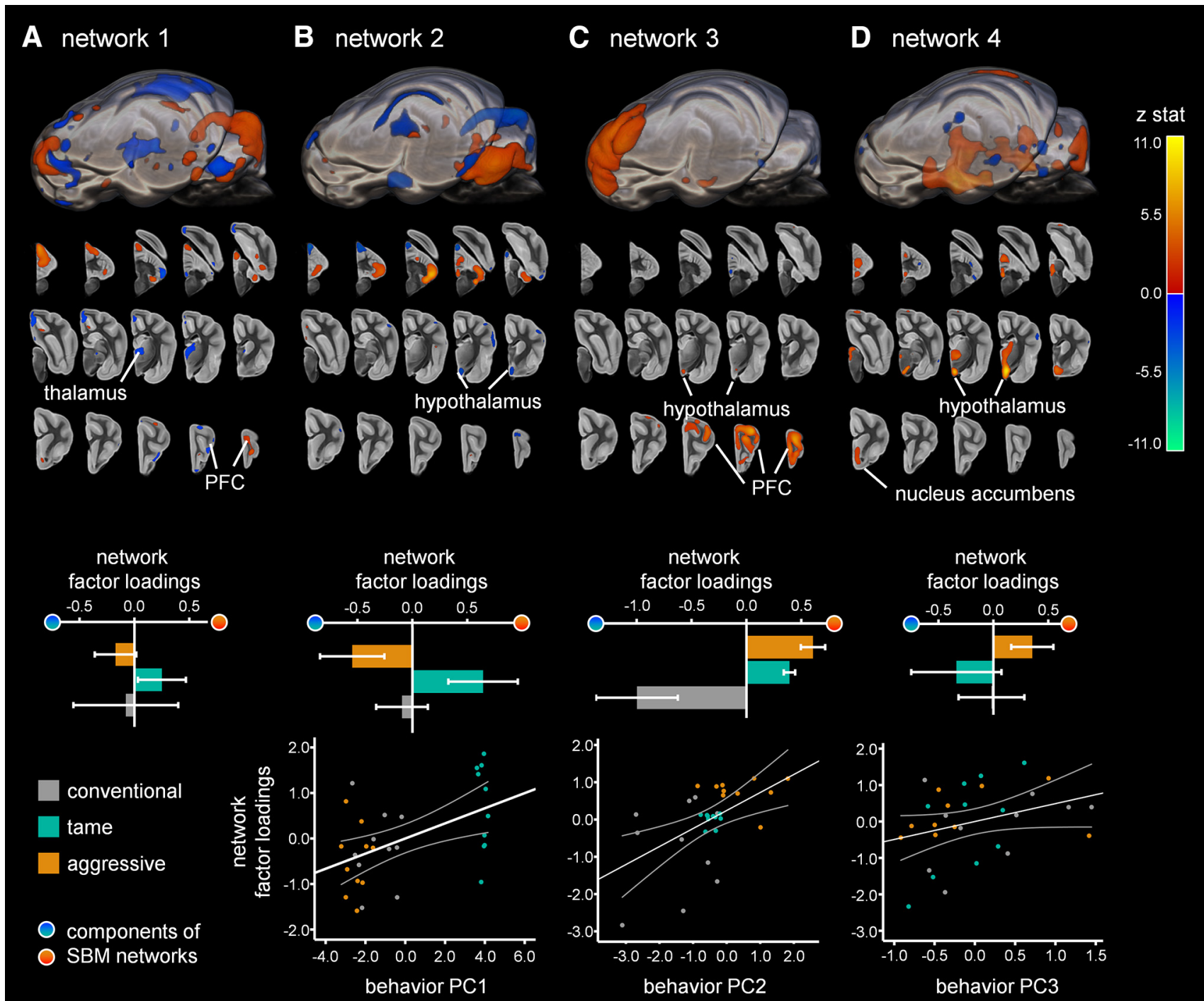

Figure 3. Regionally covarying structural brain networks and relationship to strain membership and individual behavior scores. Red-yellow and blue-green components of each network are anticorrelated; only significant voxels are shown for each network. Bar graphs represent factor loadings for each strain; positive loadings indicate larger volumes in red-yellow regions (represented with red dot), whereas negative loadings indicate larger volumes for blue-green regions (represented with blue dot). Partial regression plots represent significant relationships between factor loadings for Networks 2-4 and behavior measurements PC1-PC3 in each fox. A, Network 1 factor loadings did not differentiate between strains and were not significantly related to behavior scores. $\boldsymbol{B}$, Network 2 factor loadings differentiated between tame and aggressive strains and were significantly related to PC1 behavior scores. C, Network 3 factor loadings differentiated the tame and aggressive strains from the conventional strain and were significantly related to PC2 behavior scores. D, Network 4 factor loadings did not differentiate between strains and were marginally related to $\mathrm{PC} 3$ behavior scores.

across brain regions, as we recently documented in domestic dog breeds (Hecht et al., 2019). To probe this possibility, we used source-based morphometry, a model-free, ICA-based approach (Xu et al., 2009), to identify structurally covarying multiregion networks across the entire dataset (but white matter connectivity is not assessed with this method). This identified four significantly covarying brain networks (Fig. 3; Table 3).

We then investigated the extent to which these networks were related to strain membership and to individual behavior scores. Behavior scores were subjected to a PCA analysis, resulting in three components, each of which explains $29.0 \%, 8.0 \%$, and $6.6 \%$ of variance, respectively. We then used multiple linear regression to probe the relationship between factor loadings for these three behavior components (Table 1; Fig. 4) and our four morphometry components (Table 3 ).

Network 1 contained clusters in the thalamus, caudate, NAc, cerebellum, and other regions (Fig. 3A). Factor loadings were in opposite directions for the tame and aggressive strains but were centered near zero with wide variance in the conventional strain; however, strain-wise differences did not reach significance $\left(F_{(2,27)}=0.475, p=0.627\right)$. Multiple linear regression indicated that factor loadings for Network 1 accounted for $11.6 \%$ of the variance in behavior PCA scores, but the overall regression model did not reach significance $\left(F_{(3,26)}=1.137, p=0.352\right)$, nor did any of the partial correlations between brain and behavior factor loadings.

Network 2 was mainly comprised of one cluster that covered most of the hypothalamus, plus several other clusters scattered throughout the cerebellum. Factor loadings strongly differentiated the tame and aggressive strains from each other and were centered near zero for the conventional strain. Strain-wise differences were significant $\left(F_{(2,27)}=4.495, p=0.021\right.$; Fig. $\left.3 B\right)$. Post hoc tests using Tukey correction for multiple comparisons confirmed that factor loadings significantly differentiated the tame and 
Table 3. Clusters resulting from SBM analysis

\begin{tabular}{|c|c|c|c|c|c|}
\hline & $\begin{array}{l}\text { Cluster } \\
\text { index }\end{array}$ & $\begin{array}{l}\text { Volume } \\
\left(\mathrm{mm}^{3}\right)\end{array}$ & $\begin{array}{l}\text { MAX } \\
X \text { (vox) }\end{array}$ & $\begin{array}{l}\text { MAX } \\
Y \text { (vox) }\end{array}$ & $\begin{array}{l}\text { MAX } \\
Z \text { (vox) }\end{array}$ \\
\hline \multicolumn{6}{|l|}{ Network 1 (negative/blue) } \\
\hline & \multirow[t]{5}{*}{18} & \multirow[t]{5}{*}{137.997} & 14 & 114 & 120 \\
\hline & & & 13 & 116 & 114 \\
\hline & & & 13 & 95 & 122 \\
\hline & & & 14 & 126 & 122 \\
\hline & & & 14 & 150 & 123 \\
\hline & \multirow[t]{6}{*}{17} & \multirow{6}{*}{125.712} & 29 & 135 & 68 \\
\hline & & & 25 & 145 & 63 \\
\hline & & & 21 & 149 & 70 \\
\hline & & & 19 & 160 & 61 \\
\hline & & & 19 & 158 & 56 \\
\hline & & & 30 & 152 & 72 \\
\hline & 16 & 48.573 & 61 & 80 & 51 \\
\hline & \multirow[t]{3}{*}{15} & \multirow{3}{*}{39.312} & 52 & 218 & 53 \\
\hline & & & 44 & 210 & 34 \\
\hline & & & 52 & 204 & 44 \\
\hline & \multirow[t]{3}{*}{14} & \multirow[t]{3}{*}{17.523} & 40 & 219 & 87 \\
\hline & & & 32 & 208 & 97 \\
\hline & & & 24 & 202 & 97 \\
\hline & 13 & 8.451 & 61 & 213 & 70 \\
\hline & 12 & 6.129 & 34 & 215 & 19 \\
\hline & 11 & 5.265 & 18 & 87 & 48 \\
\hline & 10 & 5.238 & 15 & 118 & 86 \\
\hline & 9 & 5.184 & 60 & 86 & 68 \\
\hline & 8 & 2.349 & 41 & 122 & 50 \\
\hline & 7 & 1.755 & 65 & 156 & 53 \\
\hline & \multirow[t]{3}{*}{6} & \multirow[t]{3}{*}{1.188} & 66 & 195 & 57 \\
\hline & & & 69 & 192 & 61 \\
\hline & & & 70 & 190 & 62 \\
\hline & 5 & 1.053 & 26 & 209 & 85 \\
\hline & 4 & 0.837 & 54 & 155 & 51 \\
\hline & 3 & 0.567 & 33 & 233 & 30 \\
\hline & 2 & 0.459 & 18 & 107 & 56 \\
\hline & 1 & 0.432 & 78 & 99 & 69 \\
\hline \multicolumn{6}{|l|}{ Network 1 (positive/orange) } \\
\hline & \multirow[t]{6}{*}{14} & \multirow[t]{6}{*}{383.94} & 24 & 51 & 89 \\
\hline & & & 30 & 55 & 83 \\
\hline & & & 32 & 53 & 70 \\
\hline & & & 34 & 56 & 75 \\
\hline & & & 26 & 49 & 68 \\
\hline & & & 17 & 102 & 78 \\
\hline & 13 & 94.338 & 40 & 234 & 57 \\
\hline & & & 41 & 229 & 49 \\
\hline & & & 35 & 225 & 73 \\
\hline & & & 33 & 238 & 59 \\
\hline & & & 30 & 234 & 69 \\
\hline & & & 37 & 214 & 44 \\
\hline & 12 & 41.499 & 43 & 73 & 42 \\
\hline & & & 47 & 61 & 55 \\
\hline & 11 & 24.516 & 59 & 105 & 60 \\
\hline & & & 66 & 108 & 54 \\
\hline & 10 & 17.604 & 48 & 99 & 44 \\
\hline & 9 & 16.659 & 23 & 118 & 103 \\
\hline & & & 30 & 113 & 100 \\
\hline & & & 40 & 107 & 100 \\
\hline & 8 & 6.831 & 49 & 201 & 94 \\
\hline & 7 & 4.617 & 28 & 178 & 36 \\
\hline & 6 & 3.996 & 50 & 101 & 77 \\
\hline & 5 & 3.402 & 36 & 186 & 102 \\
\hline & 4 & 2.052 & 57 & 134 & 51 \\
\hline & 3 & 0.864 & 28 & 142 & 57 \\
\hline & 2 & 0.162 & 26 & 157 & 45 \\
\hline & 1 & 0.027 & 26 & 151 & 40 \\
\hline & & & & & ntinues.) \\
\hline
\end{tabular}

Table 3. Continued

\begin{tabular}{|c|c|c|c|c|c|}
\hline & $\begin{array}{l}\text { Cluster } \\
\text { index }\end{array}$ & $\begin{array}{l}\text { Volume } \\
\left(\mathrm{mm}^{3}\right)\end{array}$ & $\begin{array}{l}\text { MAX } \\
X \text { (vox) }\end{array}$ & $\begin{array}{l}\text { MAX } \\
Y \text { (vox) }\end{array}$ & $\begin{array}{l}\text { MAX } \\
Z \text { (vox) }\end{array}$ \\
\hline \multicolumn{6}{|l|}{ Network 2 (negative/blue) } \\
\hline & 9 & 153.954 & 21 & 55 & 95 \\
\hline & & & 17 & 88 & 93 \\
\hline & & & 16 & 97 & 85 \\
\hline & 8 & 40.635 & 24 & 158 & 38 \\
\hline & 7 & 39.501 & 71 & 173 & 88 \\
\hline & & & 61 & 156 & 109 \\
\hline & & & 62 & 158 & 108 \\
\hline & & & 68 & 168 & 96 \\
\hline & & & 65 & 133 & 111 \\
\hline & & & 66 & 131 & 110 \\
\hline & 6 & 33.966 & 73 & 161 & 83 \\
\hline & & & 74 & 154 & 82 \\
\hline & 5 & 25.596 & 73 & 97 & 54 \\
\hline & & & 69 & 85 & 64 \\
\hline & & & 67 & 82 & 70 \\
\hline & 4 & 12.15 & 33 & 232 & 76 \\
\hline & & & 33 & 237 & 68 \\
\hline & & & 32 & 236 & 70 \\
\hline & 3 & 9.18 & 23 & 44 & 70 \\
\hline & 2 & 0.378 & 26 & 99 & 100 \\
\hline & 1 & 0.054 & 56 & 112 & 40 \\
\hline \multicolumn{6}{|l|}{ Network 2 (positive/orange) } \\
\hline & 11 & 528.201 & 55 & 76 & 49 \\
\hline & & & 47 & 84 & 39 \\
\hline & & & 51 & 98 & 41 \\
\hline & & & 33 & 55 & 55 \\
\hline & & & 43 & 95 & 54 \\
\hline & & & 35 & 56 & 59 \\
\hline & 10 & 48.168 & 18 & 90 & 50 \\
\hline & & & 19 & 92 & 65 \\
\hline & & & 23 & 90 & 74 \\
\hline & 9 & 8.289 & 63 & 145 & 77 \\
\hline & 8 & 7.128 & 33 & 75 & 74 \\
\hline & 7 & 5.373 & 15 & 118 & 88 \\
\hline & 6 & 1.89 & 66 & 135 & 82 \\
\hline & 5 & 1.674 & 33 & 223 & 54 \\
\hline & 4 & 0.945 & 18 & 114 & 106 \\
\hline & 3 & 0.648 & 39 & 216 & 44 \\
\hline & 2 & 0.027 & 44 & 218 & 66 \\
\hline & 1 & 0.027 & 49 & 63 & 75 \\
\hline \multicolumn{6}{|l|}{ Network 3 (negative/blue) } \\
\hline & 4 & 4.428 & 17 & 90 & 53 \\
\hline & 3 & 2.241 & 22 & 47 & 55 \\
\hline & & & 23 & 43 & 58 \\
\hline & 2 & 0.729 & 18 & 95 & 62 \\
\hline & 1 & 0.324 & 19 & 89 & 74 \\
\hline \multicolumn{6}{|l|}{ Network 3 (positive/orange) } \\
\hline & 4 & 898.344 & 41 & 225 & 71 \\
\hline & & & 50 & 217 & 82 \\
\hline & & & 58 & 212 & 69 \\
\hline & & & 32 & 228 & 54 \\
\hline & & & 41 & 229 & 46 \\
\hline & & & 59 & 203 & 86 \\
\hline & 3 & 11.205 & 22 & 139 & 36 \\
\hline & 2 & 3.159 & 27 & 156 & 39 \\
\hline & 1 & 0.513 & 37 & 103 & 124 \\
\hline \multicolumn{6}{|l|}{ Network 4 (negative/blue) } \\
\hline & 14 & 14.31 & 46 & 80 & 63 \\
\hline & & & 41 & 81 & 69 \\
\hline & 13 & 12.285 & 72 & 152 & 92 \\
\hline & & & 74 & 163 & 83 \\
\hline & 12 & 9.531 & 53 & 79 & 43 \\
\hline
\end{tabular}


Table 3. Continued

\begin{tabular}{|c|c|c|c|c|c|}
\hline & $\begin{array}{l}\text { Cluster } \\
\text { index }\end{array}$ & $\begin{array}{l}\text { Volume } \\
\left(\mathrm{mm}^{3}\right)\end{array}$ & $\begin{array}{l}\text { MAX } \\
X \text { (vox) }\end{array}$ & $\begin{array}{l}\text { MAX } \\
Y \text { (vox) }\end{array}$ & $\begin{array}{l}\text { MAX } \\
Z \text { (vox) }\end{array}$ \\
\hline & & & 52 & 84 & 49 \\
\hline & 11 & 9.018 & 76 & 121 & 55 \\
\hline & 10 & 4.239 & 49 & 98 & 64 \\
\hline & 9 & 2.106 & 32 & 238 & 62 \\
\hline & 8 & 1.377 & 45 & 64 & 66 \\
\hline & 7 & 1.188 & 32 & 233 & 75 \\
\hline & 6 & 0.918 & 39 & 107 & 45 \\
\hline & 5 & 0.783 & 60 & 87 & 67 \\
\hline & 4 & 0.621 & 50 & 100 & 82 \\
\hline & 3 & 0.216 & 28 & 125 & 74 \\
\hline & 2 & 0.081 & 54 & 74 & 52 \\
\hline & 1 & 0.027 & 74 & 107 & 53 \\
\hline \multicolumn{6}{|l|}{ Network 4 (positive/orange) } \\
\hline & 12 & 452.682 & 24 & 156 & 38 \\
\hline & & & 21 & 139 & 36 \\
\hline & & & 26 & 130 & 41 \\
\hline & & & 26 & 143 & 59 \\
\hline & & & 21 & 127 & 35 \\
\hline & & & 21 & 152 & 52 \\
\hline & 11 & 184.788 & 17 & 97 & 53 \\
\hline & & & 17 & 114 & 71 \\
\hline & & & 20 & 90 & 74 \\
\hline & & & 16 & 126 & 60 \\
\hline & & & 15 & 112 & 65 \\
\hline & & & 16 & 111 & 55 \\
\hline & 10 & 98.685 & 26 & 46 & 68 \\
\hline & & & 25 & 46 & 51 \\
\hline & & & 24 & 46 & 49 \\
\hline & 9 & 26.109 & 27 & 117 & 130 \\
\hline & & & 26 & 112 & 129 \\
\hline & & & 28 & 107 & 128 \\
\hline & & & 27 & 133 & 131 \\
\hline & & & 27 & 141 & 130 \\
\hline & 8 & 10.773 & 24 & 65 & 78 \\
\hline & 7 & 10.746 & 23 & 67 & 50 \\
\hline & 6 & 1.539 & 36 & 94 & 122 \\
\hline & 5 & 0.486 & 32 & 135 & 92 \\
\hline & 4 & 0.27 & 21 & 63 & 38 \\
\hline & 3 & 0.162 & 56 & 215 & 63 \\
\hline & 2 & 0.081 & 21 & 66 & 94 \\
\hline & 1 & 0.027 & 35 & 134 & 85 \\
\hline
\end{tabular}

aggressive strains from each other $(p=0.016)$. Loading coefficients for Network 2 accounted for $31.0 \%$ of the variance in behavior scores. The overall regression model reached significance $\left(F_{(3,26)}=3.908, p=0.020\right)$. In examining partial correlations with individual behavior categories, we applied the Benjamini-Hochberg method for FDR correction. This revealed a significant partial correlation with PC1 behavior scores $(\beta=$ $0.166, t=2.964, p=0.006$, which exceeded the critical value of $0.017)$. Generally, behavioral traits with the highest positive loadings for PC1 describe tame behavior and proximity to a human approacher, whereas traits with the most negative loadings describe aggressive behavior and greater distance from a human approacher (Table 1; Fig. 4). Examination of the partial correlation scatter plot reveals that tame foxes cluster together with higher scores for both behavior and neuroanatomy, whereas aggressive and conventional foxes cluster together on the lower end of both axes (Fig. 33).

Network 3 contained two smaller, discrete clusters in the hypothalamus, plus a large cluster covering much of prefrontal and premotor cortex, including portions of the prorean, orbital, frontal, precruciate, and rostral composite gyri. For this network, factor loadings were similar for the tame and aggressive strains, and both were strongly opposite to the conventional foxes; the strain-wise difference was significant $\left(F_{(2,27)}=14.795, p<0.001\right.$; Fig. 3C). Post hoc Tukey tests revealed that this network significantly differentiated both the tame strain from the conventional strain $(p=0.001)$ and the aggressive strain from the conventional strain $(p=0.000)$. Regression analyses revealed that behavior scores accounted for $35.3 \%$ of the variance in morphometry loading coefficients. The overall regression model reached significance $\left(F_{(3,26)}=4.720, p=0.009\right)$. Examination of partial correlations using Benjamini-Hochberg FDR correction revealed that there was a significant partial correlation with PC2 $(\beta=0.483$, $t=3.251, p=0.003$, which exceeded the critical value of 0.017 ). For PC2, traits with the highest positive loadings describe active aggressive response and fox position in the front part of the cage, whereas traits with highest negative loadings describe a passive tame response: tolerance of human tactile contact and fox position in the back of the cage (Table 1; Fig. 4). Examination of the partial correlation scatter plot reveals that aggressive foxes tended to score high for both the behavior and neuroanatomical measures, whereas conventional foxes tended to score low on both, and tame foxes were tightly clustered in the intermediate range (Fig. $3 C$ ).

Network 4 contained a large cluster that spanned regions of the thalamus, most of the hypothalamus, and portions of the NAc/ventral forebrain and caudate (Fig. 3D). There were also several additional clusters located in cortex and cerebellum. Factor loadings were again opposite for the tame and aggressive strains, and centered near zero for the conventional strain; strain-wise differences did not reach significance $\left(F_{(2,27)}=1.198\right.$, $p=0.312$ ). Loading coefficients for Network 4 accounted for $14.6 \%$ of the variance in behavior scores. The overall regression model did not reach significance $\left(F_{(3,26)}=1.413, p=0.242\right)$. None of the partial correlations between morphometry and behavior scores reached significance, but there was a marginally positive relationship with PC3 $(\beta=0.492, t=1.780, p=0.087$, which did not exceed the critical value of 0.017$)$. In PC3, traits with the highest positive loadings describe neutral exploratory behavior (e.g., "ears are vertical"), whereas traits with the most negative loadings describe prosocial greeting behavior and fox position in the front part of the cage (see Table 1). Tame, aggressive, and conventional foxes showed marked overlap in both behavior and neural scores in this analysis (Fig. 3D).

\section{Discussion}

The Russian farm-fox experiment is perhaps the longest-running, best-controlled, and most well-known artificial selection study bearing on the evolution of mammalian behavior. As such, it enables a uniquely powerful window on the neural mechanisms governing behavioral adaptation. This study used high-resolution MRI to examine the brains of these foxes. We found that selection on social behavior has altered the anatomy of distributed gray matter networks, which included, among other regions, PFC, hippocampus, amygdala, caudate, NAc, cerebellum, and hypothalamus. These regions have also been implicated in past studies in these foxes (Kukekova et al., 2011b; Huang et al., 2015; Hekman et al., 2018; Wang et al., 2018; Rosenfeld et al., 2020) and in past studies on wolf-to-dog domestication (Nikulina, 1991; Saetre et al., 2004; Natt et al., 2012; Li et al., 2013; Ruan and Zhang, 2016; Spocter et al., 2018; Oshchepkov et al., 2019). 

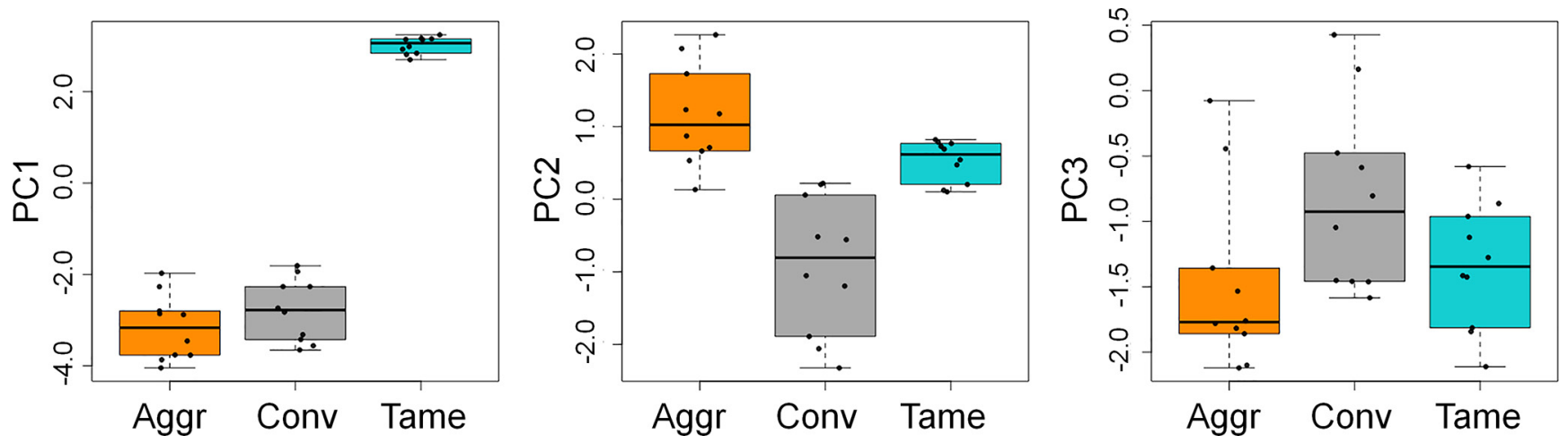

Figure 4. Population distributions for the first three PCs (PC1-PC3) of fox behavior. Aggr, "Aggressive" population; Conv, "conventional farm-bred population"; Tame, "tame" population. Black dots represent individual data points. Horizontal bars within each box represent the population median. The whiskers represent the range of data up to 1.5 times the interquartile range.

Interestingly, some of these regions are also affected by domestication in rabbits (Brusini et al., 2018).

Notably, portions of fox PFC appeared in several of our results (Figs. $2 E, 3 A, 3 C$ ). How can the functional relevance of this region be interpreted? Although some of these prefrontal results are located on the dorsolateral surface of the brain (i.e., the prorean gyrus), this region is likely not homologous to the granular dorsolateral PFC of humans and macaque monkeys, as that region is thought to be unique to primates (Preuss, 1995; Passingham and Wise, 2012). Rather, the connectivity and cytoarchitecture of carnivore PFC (Narkiewicz and Brutkowski, 1967; Kosmal and Dabrowska, 1980; Kosmal, 1981a,b; Stepniewska and Kosmal, 1986; Markow-Rajkowska and Kosmal, 1987; Rajkowska and Kosmal, 1988) are more similar to that of the dysgranular and agranular portions of primate orbitofrontal and ventromedial PFC, regions that function to integrate external multisensory and internal visceromotor information with limbic reward and threat signals to compare the value of potential behavioral choices (Carmichael and Price, 1996; Rudebeck and Murray, 2011). Putatively, this circuitry has been altered in tame foxes to bias behavioral decisions toward the reward value of social contact with humans, and in aggressive foxes toward the opposite. This interpretation fits generally with conceptualizations of partially shared circuitry between social approach and social avoidance processing in humans and other species (Aupperle and Paulus, 2010).

However, the current study also produced some findings which were unexpected and suggest revision of existing thinking about domestication. One of these was that total gray matter volume in both the tame strain and the aggressive strain is increased compared with the conventional strain. These findings are in contrast to a number of prior studies which have reported that domestication reduces brain size in diverse species including Atlantic cod (Mayer et al., 2011), guppies (Burns et al., 2009), rainbow trout (Marchetti and Nevitt, 2003), mallard ducks (Ebinger, 1995), rats, mice, gerbils, guinea pigs, rabbits, pigs, sheep, llamas, horses, ferrets, cats, and dogs (for review, see Kruska, 2005). Brain size should be interpreted in the context of body size, given that the two covary. While body size measurements were not available for the foxes in our study, Huang et al. (2015) report a $15.9 \%$ reduction in body weight in tame compared with conventional foxes, suggesting that, if anything, differences in brain:body size ratios are more pronounced than the brain measurements alone would indicate. What might cause this increase in brain size? One possible explanation might involve neuroplastic changes resulting from differential lifetime experience. The link between naturalistic, enriched environments and larger, more complex brains has been noted for decades (van Praag et al., 2000; Lambert et al., 2019). Tame, aggressive, and conventional foxes are all housed in identical conditions and undergo identical treatment with minimally necessary human interaction. Nonetheless, tame foxes, because of their innate predisposition toward prosocial interaction with humans, may effectively experience this environment to be more naturalistic and enriched.

However, this potential interpretation does not explain why the aggressive strain also shows increased gray matter volume relative to controls. Perhaps their constant drive to avoid human contact functions as a sort of enrichment, but we instead favor an alternative explanation. Both the tame and aggressive strains have been subject to intense, sustained selection on behavior, while the conventional strain undergoes no such intentional selection. Thus, it is possible that fast evolution of behavior, at least initially, may generally proceed via increases in gray matter. Several potential mechanisms might underlie this effect. First, because of developmental linkages, selection pressure for increased size in one region may "drag along" enlargement in others to some extent (Finlay et al., 2001), although it seems apparent that the current dataset also reflects at least some degree of modular evolution (i.e., focused selection pressure on specific regions and networks) (Striedter, 2020). Second, selection pressure for expansion of a particular brain region might favor genomic variants leading to changes in expression of genes with potential pleiotropic effects (e.g., transcription factors). Consequently, these gene expression changes could produce expansion not only in that one region but also in others. Normally, trade-offs with metabolic and life history constraints (Isler and van Schaik, 2009) might favor further fine-tuning of the activity of these genes so that the effect occurs more specifically only in the "targeted" brain region, but because captivity reduces the pressure for optimization, this fine-tuning might fail to occur. Third, because of the complex interdependencies between brain systems, adaptive solutions that modify one existing system may stand a high likelihood of producing deleterious effects in others unless additional compensatory adaptations also occur (De Vries, 2004). In the context of extreme selection pressure, these compensatory changes might be more likely to occur via the addition of new neural material rather than via volumetrically net-zero alterations to existing circuits, which putatively would require more fine-tuned genetic changes. In the wild, there would be constant pressure against these "easy, wasteful" solutions, but in the context of the farm-fox experiment, these constraints may have been 
lessened or removed, as these foxes are not bred for increased meat yields, more rapid maturation, or reduced feeding costs. In general, it is important to note that strong selection for a single dimension of behavior in captivity, as occurred in the farm-fox experiment, is expected to differ in important ways from selection in the wild, which occurs on many behaviors at once. Because of this, experimentally applied selection pressure might be more likely to produce "nonoptimal" brain network changes, in contrast to in the wild, where such shifts might produce detrimental effects on other behaviors, and, importantly, on animal survival. There are multiple potential cellular-level causes for increased gray matter, including increased neuron count, increased neuron size, and/ or dendritic changes, such as increased arborization or spine density (Zatorre et al., 2012; Keifer et al., 2015). Future research, including single-cell transcriptomics and histologic work, will be required to differentiate among these possibilities.

Notably, a recent skeletal morphology study did not find a significant difference in endocranial volume between tame and conventional foxes (Kistner et al., 2021). The foxes that became the progenitor population for Belyaev's study had existed in a farmed state in Russia for $\sim 50$ years (Kochergin, 1936; Vahrameyev and Belyaev, 1948); this original Russian farmed population was itself drawn largely from Eastern Canadian foxes (Statham et al., 2011; Rando et al., 2017) bred at fur farms on Prince Edward Island (Forester and Forester, 1982). Kistner et al. (2021) compared endocranial volumes of modern Russian farm-fox skulls to skulls from wild foxes, which had been collected in Canada east of Quebec between 1884 and 1952, with 70\% collected between 1894 and 1900 . This revealed that endocranial volume in the modern, conventional Russian farm-raised foxes (i.e., those bred without selection on behavior) was significantly reduced compared with the archived Canadian wild skulls. However, no significant difference was observed between modern tame and conventional strains, but notably, like the current study, Kistner et al. (2021) were unable to incorporate body size measurements into their analyses. We also do not know whether the skull morphology of conventional foxes started to show differences at the time when selection of conventional foxes for tameness in Russia began (1959) or whether it became pronounced later when the conventional population was evolving in parallel with the tame population. Together with these findings, the current study hints that the brain volume reduction associated with domestication might occur relatively quickly, before the onset of intentional selection on behavior. Further research is required to establish whether this is true.

A second surprising result from this study was that both tame and aggressive foxes showed enlargement in substantially overlapping gray matter regions, including PFC, amygdala, hippocampus, and cerebellum (Fig. 2E). In addition to these volumetric effects, we also observed strain-wise differences in the degree of morphologic covariation across distributed, multiregion networks. These latter measurements revealed links with individual variation in behavior, including in brain regions that did not show volumetric differences, notably, the hypothalamus. Additionally, Network 3 consisted primarily of the hypothalamus and PFC, two regions strongly implicated in both fox and dog domestication (Nikulina, 1991; Saetre et al., 2004; Kukekova et al., 2011b; Natt et al., 2012; Li et al., 2013; Ruan and Zhang, 2016; Spocter et al., 2018; Wang et al., 2018; Oshchepkov et al., 2019; Rosenfeld et al., 2020). In this network, factor loadings did not differentiate the tame from aggressive strains; rather, the selectively bred strains together were differentiated from the conventional strain (Fig. 3C). Together, these results indicate that selection for opposite behavioral responses (docility vs aggression) can produce similar evolved changes in the brain. This has important implications for attempts to evaluate the hypothesis that humans are ourselves self-domesticated (Sanchez-Villagra and van Schaik, 2019), given that similar neuroanatomical patterns of change could now be interpreted to support either selection for increased or decreased aggression in our lineage. Notably, Trut et al. (2017) reported some elements of the "domestication syndrome" in aggressive foxes, including altered timing of annual reproductive activity, facial foreshortening, and facial "star" marking; they thus propose that these traits might result pleiotropically from selection on either tameness or aggression (i.e., as a result of selection on social behavior generally). This calls for additional research on the neural correlates of evolved differences in both docility and aggression at the cellular and genomic levels.

The Russian farm-fox experiment represents a uniquely wellcontrolled opportunity to study the effects of specific, sustained selection on behavior. Thus, apart from questions of domestication, an additional implication of these results concerns brain evolution on a more general level. We found that intense selection on behavior can produce gross changes in distributed brain morphology extremely rapidly (within the span of well under 100 generations). This suggests that the brains of other animals on this planet, including Homo sapiens, may have undergone similarly precipitous morphologic shifts any time steep selection on behavior was experienced.

${ }^{a}$ Within each network, the negative components (shown as blue in Fig. 3) and positive components (shown as red in Fig. 3) are morphologically anticorrelated. Each component contains multiple clusters, indicated by Cluster index. Voxel coordinates are for maximum value in cluster.

\section{References}

Alexander-Bloch A, Giedd JN, Bullmore E (2013) Imaging structural co-variance between human brain regions. Nat Rev Neurosci 14:322-336.

Ashburner J, Friston KJ (2000) Voxel-based morphometry: the methods. Neuroimage 11:805-821.

Aupperle RL, Paulus MP (2010) Neural systems underlying approach and avoidance in anxiety disorders. Dialogues Clin Neurosci 12:517-531.

Avants B, Tustison N, Song G, Gee J (2009) ANTS: Advanced Open-Source Normalization Tools for Neuroanatomy. Philadelphia: Penn Image Computing and Science Laboratory.

Brune M (2007) On human self-domestication, psychiatry, and eugenics. Philos Ethics Humanit Med 2:21.

Brusini I, Carneiro M, Wang C, Rubin CJ, Ring H, Afonso S, Blanco-Aguiar JA, Ferrand N, Rafati N, Villafuerte R, Smedby O, Damberg P, Hallbook F, Fredrikson M, Andersson L (2018) Changes in brain architecture are consistent with altered fear processing in domestic rabbits. Proc Natl Acad Sci USA 115:7380-7385.

Burns J, Saravanan A, Rodd FH (2009) Rearing environment affects the brain size of guppies: lab-reared guppies have smaller brains than wild-caught guppies. Ethology 115:122-133.

Carmichael ST, Price JL (1996) Connectional networks within the orbital and medial prefrontal cortex of macaque monkeys. J Comp Neurol 371:179207.

Cavada C, Reinoso-Suárez F (1985) Topographical organization of the cortical afferent connections of the prefrontal cortex in the cat. J Comp Neurol 242:293-324.

De Vries GJ (2004) Minireview: sex differences in adult and developing brains: compensation, compensation, compensation. Endocrinology 145:1063-1068

Ebinger P (1995) Domestication and plasticity of brain organization in mallards (Anas platyrhynchos). Brain Behav Evol 45:286-300.

Evans AC (2013) Networks of anatomical covariance. Neuroimage 80:489504.

Evans H, de Lahunta A (2013) Miller's anatomy of the dog. New York: Elsevier Saunders. 
Finlay BL, Darlington RB, Nicastro N (2001) Developmental structure in brain evolution. Behav Brain Sci 24:263-278; discussion 278-308.

Forester JE, Forester AD (1982) Silver fox odyssey: history of the Canadian silver fox industry. Canada: Canadian Silver Fox Breeders Association.

Gupta CN, Turner JA, Calhoun VD (2019) Source-based morphometry: a decade of covarying structural brain patterns. Brain Struct Funct 224:3031-3044.

Hare B (2017) Survival of the friendliest: homo sapiens evolved via selection for prosociality. Annu Rev Psychol 68:155-186.

Hecht EE, Smaers JB, Dunn WD, Kent M, Preuss TM, Gutman DA (2019) Significant neuroanatomical variation among domestic dog breeds. J Neurosci 39:7748-7758.

Hekman JP, Johnson JL, Edwards W, Vladimirova AV, Gulevich RG, Ford AL, Kharlamova AV, Herbeck Y, Acland GM, Raetzman LT, Trut LN, Kukekova AV (2018) Anterior pituitary transcriptome suggests differences in ACTH release in tame and aggressive foxes. G3 (Bethesda) 8:859873.

Hopkins WD, Latzman RD, Mareno MC, Schapiro SJ, Gomez-Robles A, Sherwood CC (2019) Heritability of gray matter structural covariation and tool use skills in chimpanzees (Pan troglodytes): a source-based morphometry and quantitative genetic analysis. Cereb Cortex 29:3702-3711.

Hopkins WD, Mulholland MM, Reamer LA, Mareno MC, Schapiro SJ (2020) The role of early social rearing, neurological, and genetic factors on individual differences in mutual eye gaze among captive chimpanzees. Sci Rep 10:7412.

Huang S, Slomianka L, Farmer AJ, Kharlamova AV, Gulevich RG, Herbeck YE, Trut LN, Wolfer DP, Amrein I (2015) Selection for tameness, a key behavioral trait of domestication, increases adult hippocampal neurogenesis in foxes. Hippocampus 25:963-975.

Isler K, van Schaik CP (2009) The Expensive Brain: a framework for explaining evolutionary changes in brain size. J Hum Evol 57:392-400.

Jenkinson M, Beckmann CF, Behrens TE, Woolrich MW, Smith SM (2012) Fsl. Neuroimage 62:782-790.

Keifer OP Jr, Hurt RC, Gutman DA, Keilholz SD, Gourley SL, Ressler KJ (2015) Voxel-based morphometry predicts shifts in dendritic spine density and morphology with auditory fear conditioning. Nat Commun 6:7582.

Kistner T, Zink KD, Worthington S, Lieberman DE (2021) Geometric morphometric investigation of craniofacial morphological change in domesticated silver foxes. Sci Rep 11:2582.

Kochergin AF (1936) Breeding and maintenance of silver-black foxes and racoon dogs. Novosibirsk: Western-Siberian region publisher.

Kosmal A (1981a) Subcortical connections of the prefrontal cortex in dogs: afferents to the proreal gyrus. Acta Neurobiol Exp (Wars) 41:69-85.

Kosmal A (1981b) Subcortical connections of the prefrontal cortex in dogs: afferents to the medial cortex. Acta Neurobiol Exp (Wars) 41:339-356.

Kosmal A (2000) Organization of connections underlying the processing of auditory information in the dog. Prog Neuropsychopharmacol Biol Psychiatry 24:825-854.

Kosmal A, Dabrowska J (1980) Subcortical connections of the prefrontal cortex in dogs: afferents to the orbital gyrus. Acta Neurobiol Exp (Wars) 40:593-608.

Kosmal A, Markow G, Stepniewska I (1984) The presylvian cortex as a transitional prefronto-motor zone in dog. Acta Neurobiol Exp (Wars) 44:273287.

Kruska DC (2005) On the evolutionary significance of encephalization in some eutherian mammals: effects of adaptive radiation, domestication, and feralization. Brain Behav Evol 65:73-108.

Kukekova AV, Trut LN, Chase K, Shepeleva DV, Vladimirova AV, Kharlamova AV, Oskina IN, Stepika A, Klebanov S, Erb HN, Acland GM (2008) Measurement of segregating behaviors in experimental silver fox pedigrees. Behav Genet 38:185-194.

Kukekova AV, Trut LN, Chase K, Kharlamova AV, Johnson JL, Temnykh SV, Oskina IN, Gulevich RG, Vladimirova AV, Klebanov S, Shepeleva DV, Shikhevich SG, Acland GM, Lark KG (2011a) Mapping loci for fox domestication: deconstruction/reconstruction of a behavioral phenotype. Behav Genet 41:593-606.

Kukekova AV, Johnson JL, Teiling C, Li L, Oskina IN, Kharlamova AV, Gulevich RG, Padte R, Dubreuil MM, Vladimirova AV, Shepeleva DV, Shikhevich SG, Sun Q, Ponnala L, Temnykh SV, Trut LN, Acland GM (2011b) Sequence comparison of prefrontal cortical brain transcriptome from a tame and an aggressive silver fox (Vulpes vulpes). BMC Genomics $12: 482$.

Kukekova AV, Temnykh SV, Johnson JL, Trut LN, Acland GM (2012) Genetics of behavior in the silver fox. Mamm Genome 23:164-177.

Kukekova AV, Johnson JL, Xiang X, Feng S, Liu S, Rando HM, Kharlamova AV, Herbeck Y, Serdyukova NA, Xiong Z, Beklemischeva V, Koepfli KP, Gulevich RG, Vladimirova AV, Hekman JP, Perelman PL, Graphodatsky AS, O'Brien SJ, Wang X, Clark AG, et al. (2018) Red fox genome assembly identifies genomic regions associated with tame and aggressive behaviours. Nat Ecol Evol 2:1479-1491.

Lambert K, Eisch AJ, Galea LA, Kempermann G, Merzenich M (2019) Optimizing brain performance: identifying mechanisms of adaptive neurobiological plasticity. Neurosci Biobehav Rev 105:60-71.

Li Y, Vonholdt BM, Reynolds A, Boyko AR, Wayne RK, Wu DD, Zhang YP (2013) Artificial selection on brain-expressed genes during the domestication of dog. Mol Biol Evol 30:1867-1876.

MacHugh DE, Larson G, Orlando L (2017) Taming the past: ancient DNA and the study of animal domestication. Annu Rev Anim Biosci 5:329351.

Marchetti MP, Nevitt GA (2003) Effects of hatchery rearing on brain structures of rainbow trout, Oncorhynchus mykiss. Environ Biol Fish 66:9-14.

Markow-Rajkowska G, Kosmal A (1987) Organization of cortical afferents to the frontal association cortex in dogs. Acta Neurobiol Exp (Wars) 47:137-161.

Mayer I, Meager J, Skjæraasen JE, Rodewald P, Sverdrup G, Fernö A (2011) Domestication causes rapid changes in heart and brain morphology in Atlantic cod (Gadus morhua). Environ Biol Fish 92:181-186.

Narkiewicz O, Brutkowski S (1967) The organization of projections from the thalamic mediodorsal nucleus to the prefrontal cortex of the dog. J Comp Neurol 129:361-374.

Natt D, Rubin CJ, Wright D, Johnsson M, Belteky J, Andersson L, Jensen P (2012) Heritable genome-wide variation of gene expression and promoter methylation between wild and domesticated chickens. BMC Genomics 13:59.

Nikulina EM (1991) Neural control of predatory aggression in wild and domesticated animals. Neurosci Biobehav Rev 15:545-547.

Oshchepkov D, Ponomarenko M, Klimova N, Chadaeva I, Bragin A, Sharypova E, Shikhevich S, Kozhemyakina R (2019) A rat model of human behavior provides evidence of natural selection against underexpression of aggressiveness-related genes in humans. Front Genet 10:1267.

Passingham RE, Wise SP (2012) The neurobiology of the prefrontal cortex: anatomy, evolution, and the origin of insight. Oxford: Oxford UP.

Preuss TM (1995) Do rats have prefrontal cortex? The Rose-Woolsey-Akert program reconsidered. J Cogn Neurosci 7:1-24.

Radinsky L (1969) Outlines of canid and felid brain evolution. Ann NY Acad Sci 167:277-288.

Rajkowska G, Kosmal A (1988) Intrinsic connections and cytoarchitectonic data of the frontal association cortex in the dog. Acta Neurobiol Exp (Wars) 48:169-192.

Rando HM, Stutchman JT, Bastounes ER, Johnson JL, Driscoll CA, Barr CS, Trut LN, Sacks BN, Kukekova AV (2017) Y-chromosome markers for the red fox. J Hered 108:678-685.

Rodrigue AL, Alexander-Bloch AF, Knowles EE, Mathias SR, Mollon J, Koenis MM, Perrone-Bizzozero NI, Almasy L, Turner JA, Calhoun VD, Glahn DC (2020) Genetic contributions to multivariate data-driven brain networks constructed via source-based morphometry. Cereb Cortex 30:4899-4913.

Rosenfeld CS, Hekman JP, Johnson JL, Lyu Z, Ortega MT, Joshi T, Mao J, Vladimirova AV, Gulevich RG, Kharlamova AV, Acland GM, Hecht EE, Wang X, Clark AG, Trut LN, Behura SK, Kukekova AV (2020) Hypothalamic transcriptome of tame and aggressive silver foxes (Vulpes vulpes) identifies gene expression differences shared across brain regions. Genes Brain Behav 19:e12614.

Ruan C, Zhang Z (2016) Laboratory domestication changed the expression patterns of oxytocin and vasopressin in brains of rats and mice. Anat Sci Int 91:358-370.

Rudebeck PH, Murray EA (2011) Balkanizing the primate orbitofrontal cortex: distinct subregions for comparing and contrasting values. Ann NY Acad Sci 1239:1-13.

Saetre P, Lindberg J, Leonard JA, Olsson K, Pettersson U, Ellegren H, Bergstrom TF, Vila C, Jazin E (2004) From wild wolf to domestic dog: 
gene expression changes in the brain. Brain Res Mol Brain Res 126:198206.

Sanchez-Villagra MR, van Schaik CP (2019) Evaluating the self-domestication hypothesis of human evolution. Evol Anthropol 28:133-143.

Skoglund P, Gotherstrom A, Jakobsson M (2011) Estimation of population divergence times from non-overlapping genomic sequences: examples from dogs and wolves. Mol Biol Evol 28:1505-1517.

Smil V (2011) Harvesting the biosphere: the human impact. Popul Dev Rev 37:613-636.

Smith SM, Jenkinson M, Woolrich MW, Beckmann CF, Behrens TE, Johansen-Berg H, Bannister PR, De Luca M, Drobnjak I, Flitney DE, Niazy RK, Saunders J, Vickers J, Zhang Y, De Stefano N, Brady JM, Matthews PM (2004) Advances in functional and structural MR image analysis and implementation as FSL. Neuroimage 23 Suppl 1:S208-S219.

Spocter MA, Uddin A, Ng JC, Wong E, Wang VX, Tang C, Wicinski B, Haas J, Bitterman K, Raghanti MA, Dunn R, Hof PR, Sherwood CC, Jovanovik J, Rusbridge C, Manger PR (2018) Scaling of the corpus callosum in wild and domestic canids: insights into the domesticated brain. J Comp Neurol 526:2341-2359.

Statham MJ, Trut LN, Sacks BN, Kharlamova AV, Oskina IN, Gulevich RG, Johnson JL, Temnykh SV, Acland GM, Kukekova AV (2011) On the origin of a domesticated species: identifying the parent population of Russian silver foxes (Vulpes vulpes). Biol J Linn Soc Lond 103:168-175

Stepniewska I, Kosmal A (1986) Distribution of mediodorsal thalamic nucleus afferents originating in the prefrontal association cortex of the dog. Acta Neurobiol Exp (Wars) 46:311-322.

Striedter GF (2020) A history of ideas in evolutionary neuroscience. In: Evolutionary neuroscience (Kaas J, ed), pp 3-16. San Diego: Academic.

Trut LN, Kharlamova AV, Vladimirova AV, Herbeck YE (2017) On selection of foxes for enhanced aggressiveness and its correlated implications. Vestn VOGiS 21:392-401.

Trut L, Oskina I, Kharlamova A (2009) Animal evolution during domestication: the domesticated fox as a model. Bioessays 31:349-360.
Turner JA, Calhoun VD, Michael A, van Erp TG, Ehrlich S, Segall JM, Gollub RL, Csernansky J, Potkin SG, Ho BC, Bustillo J, Schulz SC (2012) Heritability of multivariate gray matter measures in schizophrenia. Twin Res Hum Genet 15:324-335.

Vahrameyev KA, Belyaev DK (1948) Guide for fox breeding (In Russian). Moscow: International Book.

van Praag H, Kempermann G, Gage FH (2000) Neural consequences of environmental enrichment. Nat Rev Neurosci 1:191-198.

Wang X, Pipes L, Trut LN, Herbeck Y, Vladimirova AV, Gulevich RG, Kharlamova AV, Johnson JL, Acland GM, Kukekova AV, Clark AG (2018) Genomic responses to selection for tame/aggressive behaviors in the silver fox (Vulpes vulpes). Proc Natl Acad Sci USA 115:10398-10403.

Winkler AM, Ridgway GR, Webster MA, Smith SM, Nichols TE (2014) Permutation inference for the general linear model. Neuroimage 92:381397.

Woolrich MW, Jbabdi S, Patenaude B, Chappell M, Makni S, Behrens T, Beckmann C, Jenkinson M, Smith SM (2009) Bayesian analysis of neuroimaging data in FSL. Neuroimage 45:S173-S186.

Wrangham RW (2018) Two types of aggression in human evolution. Proc Natl Acad Sci USA 115:245-253.

Xu L, Groth KM, Pearlson G, Schretlen DJ, Calhoun VD (2009) Source-based morphometry: the use of independent component analysis to identify gray matter differences with application to schizophrenia. Hum Brain Mapp 30:711-724.

Zatorre RJ, Fields RD, Johansen-Berg H (2012) Plasticity in gray and white: neuroimaging changes in brain structure during learning. Nat Neurosci $15: 528-536$

Zeder MA (2012) Pathways to animal domestication. In: Biodiversity in agriculture: domestication, evolution, and sustainability, pp 227-259. Cambridge: Cambridge University Press.

Zhang Y, Brady M, Smith S (2001) Segmentation of brain MR images through a hidden Markov random field model and the expectation-maximization algorithm. IEEE Trans Med Imaging 20:45-57. 